\title{
Phylogenetic structure of communities between temperate and tropical regions: Exploring patterns through literature datasets
}

\author{
Clarissa Araujo Martins ${ }^{\mathrm{a}, \mathrm{e}, *}$, Maurício Silveira ${ }^{\mathrm{a}}$, Victor S. Saito ${ }^{\mathrm{b}}$, Raul Costa-Pereira ${ }^{\mathrm{c}, \mathrm{d}}$, \\ Larissa Sayuri Moreira Sugai ${ }^{c, d}$, Olivier Pays ${ }^{\mathrm{e}}$, Fabio de Oliveira Roque ${ }^{\mathrm{a}, \mathrm{f}}$ \\ ${ }^{\text {a }}$ Programa de Pós-Graduação em Ecologia e Conservação Universidade Federal de Mato Grosso do Sul, Campo Grande, MS, Brazil \\ ${ }^{\mathrm{b}}$ Departamento de Ciências Ambientais, Universidade Federal de São Carlos, São Carlos, SP, Brazil \\ ${ }^{\mathrm{c}}$ Instituto de Biociências, Universidade Estadual Paulista (Unesp), Rio Claro, SP, Brazil \\ d Programa de Pós-Graduação em Ecologia e Biodiversidade, Universidade Estadual Paulista (Unesp), Rio Claro, Brazil \\ e UMR 6554 CNRS, LETG-Angers, Université d'Angers, Angers, France \\ ${ }^{\mathrm{f}}$ Centre for Tropical Environmental and Sustainability Science and College of Science and Engineering, James Cook University, Cairns, Australia
}

\section{A R T I C L E I N F O}

\section{Keywords:}

Metazoans

Microorganisms

Phylogenetic clustering

Phylogenetic overdispersion

Plants

Tropical and temperate regions

\begin{abstract}
A B S T R A C T
Latitudinal patterns of diversity are one of the most striking large-scale biological phenomena and several hypotheses have been proposed to explain them. Using data from literature-surveys we investigated how phylogenetic patterns in microorganisms, plants, and, metazoans communities differ between the tropical and temperate regions and then explored possible ecological and evolutionary process that could shape such patterns. Using the Net Relatedness Index, we analyzed data from 1486 biological communities, collected in 32 articles that considered the phylogenetic structure of biological communities. We found a pattern of phylogenetic clustering in both regions for microorganisms, while for plants we found phylogenetic clustering in temperate regions and phylogenetic overdispersion in the tropics. We did not detect a clear pattern of clustering or overdispersion in tropical or temperate regions in metazoans. From these patterns we explore different ecological and evolutionary processes that have shaped these communities over space and time.
\end{abstract}

\section{Introduction}

The long-standing interest in spatial arrangement of biodiversity has fueled a rich debate concerning the origins and maintenance of largescale ecological patterns. Undoubtedly, species interact in complex ways and are distributed heterogeneously across the planet, but the drivers of these patterns are still unresolved (Gaston, 2000). Studies contrasting general patterns from tropical and temperate regions can shed light on the mechanisms that shape overall species diversity (e.g. Willig et al., 2003; Duarte et al., 2014; Siqueira et al., 2016). Greater species richness in tropical regions is one of the most consistent biogeographical patterns across taxa, yet the mechanisms underlying these patterns and processes are still debated (Hillebrand, 2004; Brown, 2014).

Several hypotheses have been proposed to explain latitudinal patterns (Brown, 2014), including that lower diversity of temperate regions is the result of extinctions caused by successive glacial periods (Dobzhansky, 1950; Fischer, 1960; Araújo and Costa-Pereira, 2013). In other words, climatic instability acts as a strong environmental filter, decreasing the number of species and lineages with increasing latitude. Furthermore, speciation rates are higher in the tropics, and historically a relatively small number of tropical species expanded their ranges to colonize temperate regions with harsh climatic conditions (Wiens and Donoghue, 2004; Ricklefs, 2006; Mittelbach et al., 2007; Schemske et al., 2009; Qian et al., 2013). Moreover, the greater role of biotic interactions (e.g. competition, predation, natural enemies) in the tropics can promote coevolution in interacting species because the optimum phenotype constantly changes (Mittelbach et al., 2007). This might result in faster adaptation and speciation, and consequently increase the opportunity for evolutionary novelty and diversity in tropical regions (Schemske et al., 2009).

Biogeographers and ecologists have developed several tools to investigate how ecological and evolutionary processes have shaped contemporary biodiversity patterns. Remarkably, community phylogenetics approaches have emerged as one of these tools in the recent decades. Since Webb's seminal paper on community phylogenetics (Webb, 2000), a number of studies have described phylogenetic patterns of communities across a wide range of taxa and geographical

\footnotetext{
* Corresponding author. Current address: Instituto de Biociências, INBIO, Universidade Federal do Mato Grosso do Sul, UFMS, Cidade Universitária Universitário - Pioneiros, Campo Grande, MS, 79070-900, Brazil.

E-mail address: martins.ca2@gmail.com (C. Araujo Martins).
} 


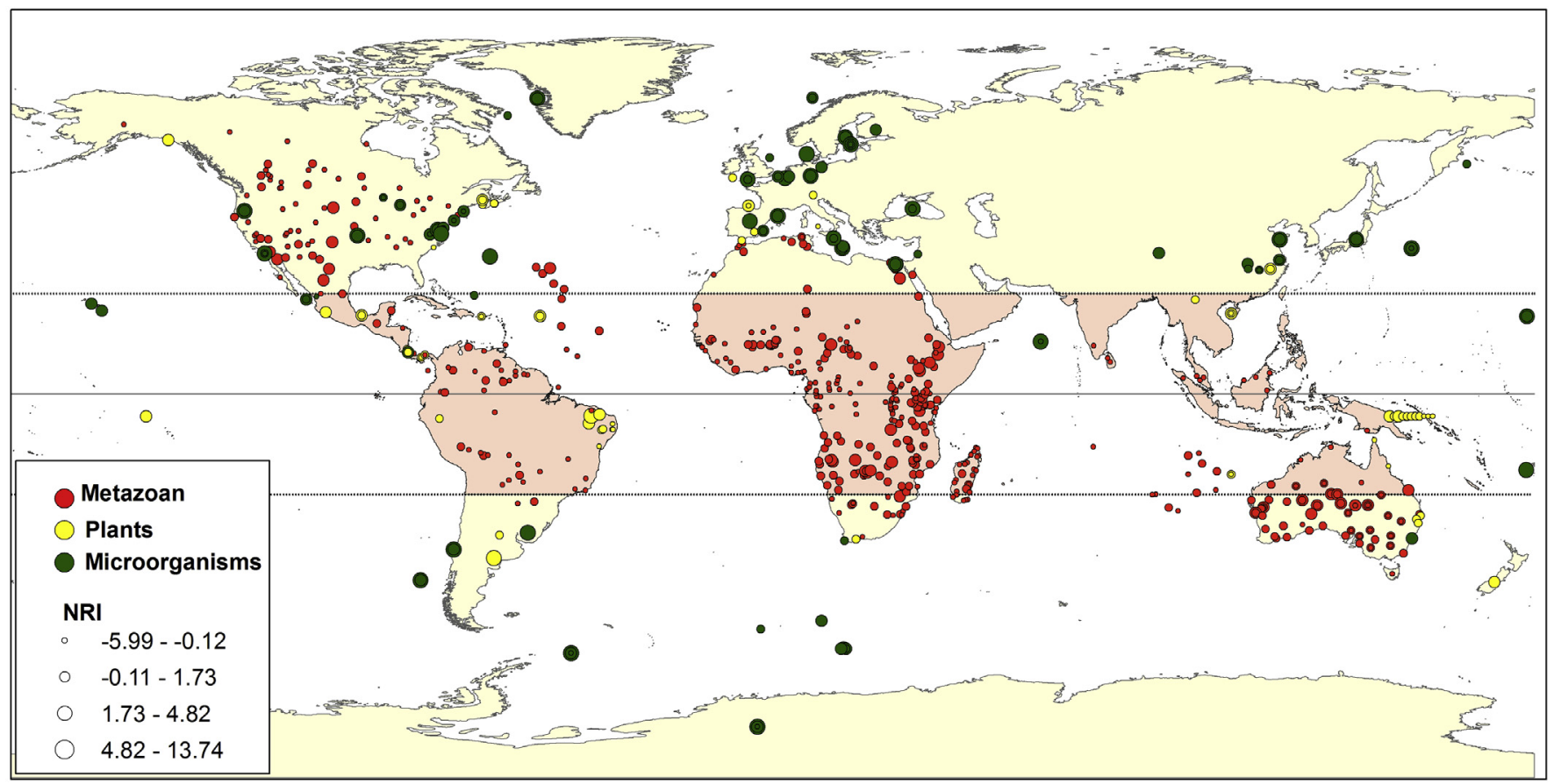

Fig. 1. Distribution of Net Relatedness Index (NRI) values from 1486 biological communities from different regions of the world. Data compiled from 32 articles (see Appendix A, Supplementary Data Table S1).

regions (Letcher, 2009; Barberán and Casamayor, 2010; ArroyoRodríguez et al., 2012; Kamilar et al., 2015; Martins et al., 2015). The community phylogenetics approach is based on Darwin's seminal idea that competition is more intense between closely related species (Cavender-Bares et al., 2009). As a consequence, phylogenetic distances are translated into ecological similarity between species. Therefore, a straightforward interpretation of community phylogenetics depends on phylogenetic niche conservatism, where ecological traits are conserved across evolutionary time (Webb et al., 2002; Pereira and Palmeirim, 2013).

Community phylogenetic structure can emerge in three major patterns: clustered, overdispersed and random. Phylogenetic clustering can occur when communities are comprised by ecologically similar species co-ocurrent at the same place and time as a result of environmental selection, while phylogenetic overdispersion may arise from limiting similarity between closely-related, and therefore competing species (Webb et al., 2002). A random phylogenetic structure results from cooccurrence patterns regardless of phylogenetic relatedness between species (Letcher, 2009). Although there is strong evidence that communities assemble in non-random phylogenetic patterns (Cadotte et al., 2017), the drivers of differences in phylogenetic structure between tropical and temperate regions remain poorly explored. Indeed, low species diversity in temperate regions would be a result of climate instability, whereas the high diversity observed in the tropics would be shaped by stronger biotic interactions. Although inferring the nature of distinct operating ecological processes from pattern description can be a drawback (Cadotte et al., 2017), convincing evidence of non-random patterns can help to clarify the drivers responsible of similar patterns of biodiversity (Vamosi et al., 2009), or at least guide the construction of better informed hypothesis. However, this framework should be analyzed with caution, because different processes can generate the same pattern. For example, strong asymmetric competition and convergent traits can also generate patterns of phylogenetic clustering (Saito et al., 2016). Furthermore, outcomes may differ depending on the scale, quality of phylogenies, lack of consideration of models of trait evolution, null model used in the analysis, presence or absence of phylogenetic signals, and absence of sufficient niche space in experimental and observational studies (Gerhold et al., 2015; Cadotte et al., 2017).

Here, we investigate how the phylogenetic structure of microorganisms, plants, and metazoans varies across tropical and temperate regions. Our goal is to describe patterns of community phylogenetic structure in tropical vs. temperate regions using observational data obtained from the literature, and explore potential ecological and evolutionary processes that may shape biodiversity patterns in these regions. Considering the classic idea of climate instability in temperate regions as a major structuring force of communities (Dobzhansky, 1950; Fischer, 1960; Araújo and Costa-Pereira, 2013), we expect to find phylogenetic clustering in biological communities for all studied groups. On the other hand, considering that in tropical regions the role of biotic interactions may be play an important role, we expect to find the overdispersion phylogenetic pattern predominating in tropical biological communities.

\section{Material and methods}

We reviewed the scientific literature that used the Net Relatedness Index (NRI) to evaluate the phylogenetic structure of biological communities (Webb et al., 2002). The NRI is the effective size of mean phylogenetic distances (MPD) among all species within an assemblage compared to a null model that deconstructs the phylogenetic structure of such communities. Positive values indicate that MPD is lower than expected under a null model (clustering), whereas negative values indicate a higher MPD than under a null model (overdispersion) (Webb et al., 2002). The NRI uses phylogenetic distances between all pairs of species in the sample to generate the phylogenetic structure of a community. We focused in this index in our study because we aim to assess general patterns of large-scale taxonomic groups. We searched the literature available on the Web of Science database (Thomson ISI) using a combination of keywords "phyloge* overdispers*" or "cluster*" and "communit", and gathered articles that provided accurate NRI values in the following areas: Environmental Sciences, Ecology, Zoology, Evolutionary Biology, Plant Sciences, Entomology, and Biodiversity Conservation. Our research resulted in 2217 articles. Then we selected only articles that met the following criteria: (i) NRI was calculated for in 
situ communities and (ii) geographical coordinates were provided for study sites. All gathered information was filtered (quality checking) for: 1) doubtful geographic information on sampling localities; 2) data lacking reliable latitude-longitude information; 3) terrestrial data locations located oceanically. All such data was considered unreliable and was disregarded.

We identified 32 articles that provided adequate NRI values for our analyses. Together they covered 1486 biological communities across a variety of taxonomic groups, including bacteria, plants, insects, amphibians, birds, and mammals distributed in tropical and temperate regions (Fig. 1, and see Appendix A, Supplementary Data Table S1). For the sake of generality, we categorized this information into three major groups (microorganisms, plants, and metazoans). This approach allowed us to assess general patterns for the major evolutionary lineages on Earth and provide sufficient replicates within each group to guarantee analytical robustness. For each article, we also extracted the null model method used for each analysis. We identified four methods used to assess null models (the most used method was the model "Species in each sample become random draws from phylogeny pool"). We also categorized the geographical coordinates of the sampling sites. We classified latitude (lat) into two classes: tropical region (with lat <

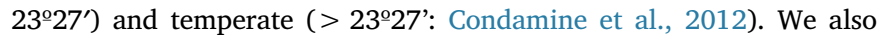
classified longitude (long) into three classes: American $\left(-158^{\circ}<\right.$ long $\left.<-45^{\circ}\right)$, European and African $\left(112^{\circ}<\right.$ long $\left.<178^{\circ}\right)$, Asian and Oceanian continent $\left(-4^{\circ}<\right.$ long $\left.<64^{\circ}\right)$ (Fig. 1) (Kamilar and Guidi, 2010). All data are reported as appendix A, supplementary data (Supplementary Data Table S1).

For each major group, we ran a linear mixed-effect model that included region (tropical vs. temperate), continent (America vs. Europe and Africa vs. Asia and Oceania), and the two-way interaction region $\times$ continent as independent variables. Since the null model method used might influence the difference between the observed NRI values and those expected under the null hypothesis (i.e. no pattern of phylogenetic dispersion) (Miller et al., 2016), we included the null model method as a random factor to control the effect of this variable in our analysis. Analyses were performed using the "nlme" package in R 3.3.0 (R Development Core Team, 2015).

\section{Results}

We found different phylogenetic patterns in the major biodiversity groups (Table 1, Fig. 2). For microorganisms, in both regions NRI was significantly positive and there was no difference in values between tropical and temperate sites (temperate region $2.143 \pm 0.159$, $\mathrm{p}<0.0001$, tropical region: $2.408 \pm 0.423, \mathrm{p}=0.01$ ), indicating a phylogenetic clustered pattern in both regions. We also detected a significant effect for the two-way interaction region $\times$ continent. The effect of region $\times$ continent interaction on the microorganism NRI indicated that continent influences the extent of the difference in NRI between temperate and tropical regions.

For plants, NRI was significantly negative in the tropics, while significantly positive in the temperate region. These values indicate a clustered and overdispersed phylogenetic pattern, respectively (Table 1, Fig. 2). In addition, we detected a significant effect for the two-way interaction in plants.

In metazoans, the intercept of the model did not differ from zero, indicating that there are no clear differences of phylogenetic patterns in metazoan communities between tropical and temperate regions. The region effect and region $x$ continent interactions were also not significant. However, we detected a significant effect with continent for metazoans, and the Asia-Oceania continents were more significantly overdispersed (Asia-Oceania: $-0.653 \pm 0.73 \mathrm{p}<0.001$, Table 1).

\section{Discussion}

Our results show that major groups of life on Earth have different patterns of clustering and phylogenetic overdispersion between tropical and temperate regions. Our finding was that the microorganisms were phylogenetically clustered in both regions, while for plants we found phylogenetic clustering in temperate regions and phylogenetic overdispersion in the tropics. We did not detect a clear pattern phylogenetic in tropical or temperate regions in metazoans. Although there is a tremendous taxonomic and functional diversity within these groups and classifying them into three broad groups (microorganisms, plants, and metazoans) has clearly oversimplified taxonomic diversity, the species within these groups may have common internal traits. For example, traits related to mobility and body size, which are important proxies for metabolism and speciation rates (Cushman et al., 1993; Isaac et al., 2005), are likely central to the understanding of the observed patterns. Indeed, our results suggest that microorganisms, the group with the smallest body size, have communities that exhibit predominantly phylogenetic clustered pattern, whereas organisms sessile in adult stage (such as land plants) are phylogenetically clustered in temperate regions.

The phylogenetic clustering observed for microorganisms in both regions may be related to stronger action of abiotic filtering in this group. It is commonly recognized that environmental filtering processes are the main drivers of phylogenetic structure of microorganism assemblages (Stegen et al., 2012), because such forces play a greater role in structuring their composition than dispersal limitation (BaasBecking, 1934; de Wit and Bouvier, 2006; but see Chytrý et al., 2012). Moreover, a strong pattern of phylogenetic clustering for microorganism communities may be related to their faster rate of evolution in comparison to eukaryotes, which in turn may be related to the higher frequency of horizontal gene transfer and low recombination levels due to the absence of sexual reproduction in the majority of such evolutionary units (Levin and Bergstrom, 2000). Additionally, the short life cycles and the larger population sizes of microorganisms favors a faster fixation of adaptive alleles (Levin and Bergstrom, 2000), which may also result in higher rates of speciation and increased co-occurrence of recently diverged lineages.

As expected, we found a pattern of phylogenetic clustering in temperate regions and phylogenetic overdispersion in the tropics for plants. Based on a classical phylogenetic framework (Webb et al., 2002), a potential explanation for this pattern is that climatic instability acts as a filter in the plant communities of temperate regions (but see Gerhold et al., 2015). In addition to environmental filtering, other processes may also explain the phylogenetic clustering observed in temperate plants. For instance, angiosperms originated and initially diversified in tropical regions (Davies et al., 2004), the lineages that colonized the temperate regions were those with ecological traits that allowed successful dispersal into drier and colder environments (Donoghue, 2008). Subsequent diversification, associated with niche conservatism, would have then triggered a pattern of phylogenetic clustering for angiosperms in temperate regions (Donoghue, 2008). Conversely, we found a phylogenetically overdispersed pattern in tropical regions. This would suggest that biotic interactions constitute the primary selective pressures for plants in the tropics, consequently increasing the phylogenetic overdispersion (but see Gerhold et al., 2015). Furthermore, in tropical regions, beyond the higher productivity, a warm, relatively stable, and wet climate, allows the coexistence of more species of plants, and can generate phylogenetic overdispersion. Increased phylogenetic dispersion in the tropics may also result from lower extinction rate for the region (i.e., ancient clades still co-occur), supporting the idea of the tropics as lineage museums (Davies et al., 2004; Donoghue, 2008).

Continents was the only factor that explained part of the variation in the patterns in extent of overdispersion for metazoans in the AsiaOceania region. This finding is somewhat surprising and provides insights for future research. For example, in the continental scale, these phylogenetic patterns may provide evidence of high intra-continental diversification or allopatric speciation (Kooyman et al., 2011; Lanier et al., 2013). Additionally, phylogenetic overdispersion may be related 
Table 1

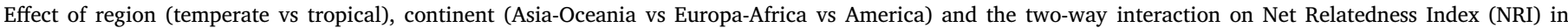

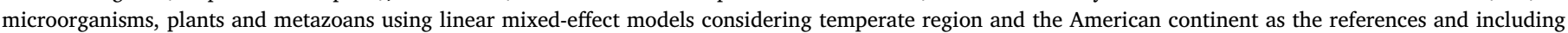

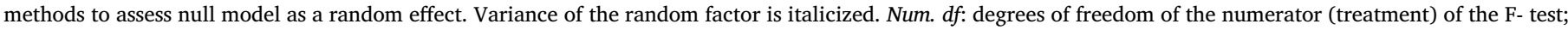
Den. $d f$ : degrees of freedom of the denominator (residuals) of the F-test.

\begin{tabular}{|c|c|c|c|c|c|}
\hline Factors & Num. $D f$ & Den. $D f$ & F-value & p-value & Coeff \pm SE \\
\hline \multicolumn{6}{|l|}{ a) Microorganisms } \\
\hline Intercept & & & & 0.01 & $2.408 \pm 0.423$ \\
\hline Region & 1 & 352.87 & 0.037 & 0.846 & Tropical: $-1.466 \pm 0.588$ \\
\hline Continent & 2 & 352.91 & 1.339 & 0.263 & $\begin{array}{l}\text { Asia-Oceania: }-0.748 \pm 0.449 \\
\text { Europe-Africa: }-0.138 \pm 0.355\end{array}$ \\
\hline Region $\mathrm{x}$ Continent & 1 & 353.37 & 7.270 & 0.007 & $\begin{array}{l}\text { Tropical Asia-Oceania: } 3.158 \pm 0.171 \\
(0.007)\end{array}$ \\
\hline Methods to assess null model & 0.517 & & & & \\
\hline \multicolumn{6}{|l|}{ b) Plants } \\
\hline Intercept & & & & 0.01 & $1.061 \pm 0.389$ \\
\hline Region & 1 & 152.873 & 5.076 & 0.025 & $\begin{array}{l}\text { Tropical: }-1.290 \pm 0.368 \\
(>0.001)\end{array}$ \\
\hline Continent & 2 & 156.470 & 0.096 & 0.908 & $\begin{array}{l}\text { Asia-Oceania: }-0.274 \pm 0.363 \\
\text { Europe-Africa: }-0.809 \pm 0.416\end{array}$ \\
\hline Region $\mathrm{x}$ Continent & 2 & 79.236 & 4.133 & 0.019 & $\begin{array}{l}\text { Tropical Asia-Oceania: } 0.622 \pm 0.409(0.129) \\
\text { Tropical Europe-Africa: } 1.871 \pm 0.654(0.006)\end{array}$ \\
\hline Methods to assess null model & 0.339 & & & & \\
\hline \multicolumn{6}{|l|}{ c) Metazoans } \\
\hline Intercept & & & & 0.417 & $0.246 \pm 0.270$ \\
\hline Region & 1 & 658.47 & 0.858 & 0.354 & Tropical: $-0.380 \pm 0.270$ \\
\hline Continent & 2 & 579.24 & 3.807 & 0.022 & $\begin{array}{l}\text { Asia-Oceania: }-0.653 \pm 0.73(<0.001) \\
\text { Europe-Africa: }-0.275 \pm 0.220(0.211)\end{array}$ \\
\hline Region $\mathrm{x}$ Continent & 2 & 663.04 & 2.937 & 0.053 & $\begin{array}{l}\text { Tropical Asia-Oceania: } 0.563 \pm 0.232 \\
\text { Tropical Europe-Africa: } 0.305 \pm 0.245\end{array}$ \\
\hline Methods to assess null model & 0.407 & & & & \\
\hline
\end{tabular}

to recent extinctions within older co-occurring clades (Kamilar and Guidi, 2010). We acknowledge, however, that using a broad approach of metazoans as a model in this study may have masked the considerable variation between groups of metazoans in important biological traits and life histories, such as size, mobility and evolutionary rates, all of which can influence phylogenetic community signals. For a reliable understanding of phylogenetic community patterns in metazoans, we believe that the deconstruction of the communities seems to be more critical than for plants and microorganisms. For example, to understand large-scale phylogenetic patterns for metazoans, it might be more appropriate to use distinct levels of biological hierarchy or ecological groups (e.g. diet, body size, or geographic distribution; or evolutionary
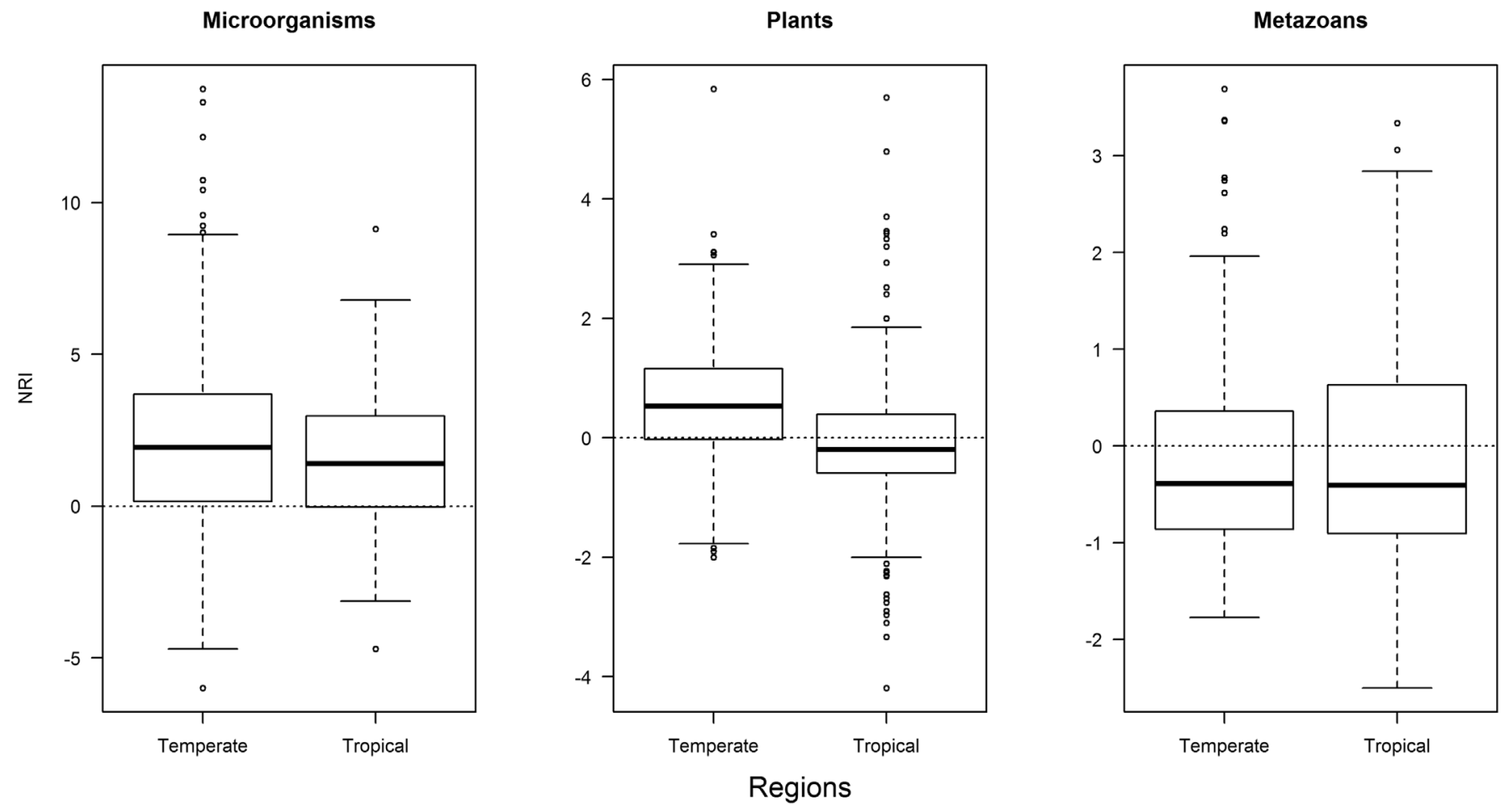

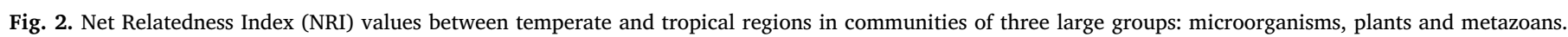


groups) because this refinement may reveal patterns potentially masked when pooling all species of large groups (Marquet et al., 2004; DinizFilho et al., 2012). Furthermore, it is possible that observed patterns are partially a result of sampling artifacts related to different intensities in collecting efforts on different continents. We believe that this shortfall might be especially relevant for highly diverse and often under-studied metazoans groups, such as insects in tropical forests. Consequently, the availability of data for multiple taxa from different continents is still a limitation for global-scale analyses.

In summary, our results indicate that the phylogenetic community patterns across latitudinal regions left different signatures within the largest biological groups on Earth. The different patterns may emerge by both ecological aspects (e.g. key traits characterizing each group) and evolutionary processes, which, together, could interactively mold current biodiversity phylogenetic patterns.

\section{Author contributions}

CAM, RCP, FOR conceived the study. CAM led the writing. CAM, MS and OP performed the statistical analyses. All authors drafted or revised the manuscript.

\section{Funding}

This research was supported by CAPES, CAPES - Cofecub, (CAM, MS, FOR, OP), gs3:CNPq and FAPESP (LSSM \#2015/25316-6, VSS \#2013/20540-0, \#2014/24532-4, \#2016/14611-0, RCP \#2014/ 20924-5).

\section{Appendix A. Supplementary data}

Supplementary data related to this article can be found at http://dx. doi.org/10.1016/j.actao.2018.05.010.

\section{References}

Araújo, M., Costa-Pereira, R., 2013. Latitudinal gradients in intraspecific ecological diversity. Biol. Lett. 9, 6-10.

Arroyo-Rodríguez, V., Cavender-Bares, J., Escobar, F., Melo, F.P.L., Tabarelli, M., Santos, B.A., 2012. Maintenance of tree phylogenetic diversity in a highly fragmented rain forest. J. Ecol. 100, 702-711.

Baas-Becking, L.G.M., 1934. Geobiologie of Inleiding Tot Demilieukunde. Van Stockum WP \& Zoon NV, Den Haag, Netherlands.

Barberán, A., Casamayor, E.O., 2010. Global phylogenetic community structure and $\beta$-diversity patterns in surface bacterioplankton metacommunities. Aquat. Microb. Ecol. 59, 1-10.

Brown, J.H., 2014. Why are there so many species in the tropics? J. Biogeogr. 41, 8-22. Cadotte, M.W., Davies, J.T., Peres-Neto, P.R., 2017. Why phylogenies do not always predict ecological differences. Ecol. Monogr. 0, 1-17.

Cavender-Bares, J., Kozak, K.H., Fine, P.V.A., Kimbel, S.W., 2009. The merging of community ecology and phylogenetic biology. Ecol. Lett. 12, 693-715.

Chytrý, M., Lososová, Z., Horsák, M., Uher, B., Čejka, T., Danihelka, J., Fajmon, K., Hájek, O., Juřičková, L., Kintrová, K., Láníková, D., Otýpková, Z., Řehořek, V., Tichý, L., 2012. Dispersal limitation is stronger in communities of microorganisms than macroorganisms across Central European cities. J. Biogeogr. 39, 1101-1111.

Condamine, F.L., Sperling, F.A.H., Wahlberg, N., Rasplus, J.Y., Kergoat, G.J., 2012. What causes latitudinal gradients in species diversity? Evolutionary processes and ecological constraints on swallowtail biodiversity. Ecol. Lett. 15, 267-277.

Cushman, J.H., Lawton, J.H., Manly, B.F.J., 1993. Latitudinal patterns in European ant assemblages: variation in species richness and body size. Oecologia 18, 30-37.

Davies, T.J., Barraclough, T.G., Chase, M.W., Soltis, P.S., Soltis, D.E., Savolainen, V., 2004. Darwin's abominable mystery: insights from a supertree of the angiosperms. Proc. Natl. Acad. Sci. U.S.A. 101, 1904-1909.

de Wit, R., Bouvier, T., 2006. 'Everything is everywhere, but, the environment selects' what did Baas Becking and Beijerinck really say? Environ. Microbiol. 8, 755-758.

Diniz-Filho, J.A.F., Rangel, T.F., Santos, M.R., 2012. Extreme deconstruction supports niche conservatism driving New World bird diversity. Acta Oecol. 43, 16-21.

Dobzhansky, T., 1950. Evolution in the tropics. Am. Sci. 38, 209-221.

Donoghue, M.J., 2008. A phylogenetic perspective on the distribution of plant diversity. Proc. Natl. Acad. Sci. U.S.A. 105, 11549-11555.

Duarte, L.D.S., Both, C., Debastiani, V.J., Carlucci, M.B., Gonçalves, L.O., Cappelatti, L., Seger, G.D.S., Bastazini, V.A.G., Brum, F.T., Salengue, E.V., Bernardo-Silva, J.S.,

2014. Climate effects on amphibian distributions depend on phylogenetic resolution and the biogeographical history of taxa. Global Ecol. Biogeogr. 23, 213-222.

Fischer, A.G., 1960. Latitudinal variations in organic diversity. Evolution 14, 64-81.

Gaston, K.J., 2000. Global patterns in biodiversity. Nature 405, 220-227.

Gerhold, P., Cahill, J.F., Winter, M., Bartish, I.V., Prinzing, A., 2015. Phylogenetic patterns are not proxies of community assembly mechanisms (they are far better). Funct. Ecol. 29, 600-614.

Hillebrand, H., 2004. On the generality of the latitudinal diversity gradient. Am. Nat. 163, $192-211$.

Isaac, N.J.B., Jones, K.E., Gittleman, J.L., Purvis, A., 2005. Correlates of species richness in mammals: body size, life history, and ecology. Am. Nat. 165, 600-607.

Kamilar, J.M., Guidi, L.M., 2010. The phylogenetic structure of primate communities: variation within and across continents. J. Biogeogr. 37, 801-813.

Kamilar, J.M., Beaudrot, L., Reed, K.E., 2015. Climate and species richness predict the phylogenetic structure of African mammal communities. PLoS One 4, e0121808.

Kooyman, R., Rossetto, M., Cornwell, W., Westoby, M., 2011. Phylogenetic tests of community assembly across regional to continental scales in tropical and subtropical rain forests. Global Ecol. Biogeogr. 20, 707-716.

Lanier, H.C., Edwards, D.L., Knowles, L.L., Riddle, B., 2013. Phylogenetic structure of vertebrate communities across the Australian arid zone. J. Biogeogr. 40, 1059-1070.

Letcher, S.G., 2009. Phylogenetic structure of angiosperm communities during tropical forest succession. Proc. Biol. Sci. 277, 97-104.

Levin, B.R., Bergstrom, C.T., 2000. Bacteria are different: observations, interpretations, speculations, and opinions about the mechanisms of adaptive evolution in prokaryotes. Proc. Natl. Acad. Sci. U.S.A. 97, 6981-6985.

Marquet, P.A., Fernández, M., Navarrete, S.A., Valdovinos, C., 2004. Diversity emerging: toward a deconstruction of biodiversity patterns. In: Lomolino, M., Heaney, L.R. (Eds.), Frontiers of Biogeography: New Directions in the Geography of Nature. Sinauer Associates, Massachusetts, pp. 191-209.

Martins, C.A., Roque, F.O., Santos, B.A., Ferreira, V.L., Strüssmann, C., Tomas, W.M., 2015. What shapes the phylogenetic structure of anuran communities in a seasonal environment? The influence of determinism at regional scale to stochasticity or antagonistic forces at local scale. PLoS One 10, e0130075.

Miller, E.T., Farine, D.R., Trisos, C.H., 2016. Phylogenetic community structure metrics and null models: a review with new methods and software. Ecography 39, 1-17.

Mittelbach, G.G., Schemske, D.W., Cornell, H.V., Allen, A.P., Brown, J.M., Bush, M.B., Harrison, S.P., Hurlbert, A.H., Knowlton, N., Lessios, H.A., McCain, C.M., McCune, A.R., McDade, L.A., McPeek, M.A., Near, T.J., Price, T.D., Ricklefs, R.E., Roy, K., Sax, D.F., Schluter, D., Sobel, J.M., Turelli, M., 2007. Evolution and the latitudinal diversity gradient: speciation, extinction and biogeography. Ecol. Lett. 10, 315-331.

Pereira, M.J., Palmeirim, J.M., 2013. Latitudinal diversity gradients in New World bats: are they a consequence of niche conservatism? PLoS One 8, e69245.

Qian, H., Zhang, Y., Zhang, J., Wang, X., 2013. Latitudinal gradients in phylogenetic relatedness of angiosperm trees in North America. Global Ecol. Biogeogr. 22, $1183-1191$.

R Development Core Team, 2015. R: a Language and Environment for Statistical Computing. R Foundation for Statistical Computing, Vienna, Austria. https://www. R-project.org/.

Ricklefs, R.E., 2006. Evolutionary diversification and the origin of the diversity-environment relationship. Ecology 87, S3-S13.

Saito, V.S., Valente-Neto, F., Rodrigues, M.E., Roque, F.O., Siqueira, T., 2016. Phylogenetic clustering among aggressive competitors: evidence from Odonate assemblages along a riverine gradient. Oecologia 182, 219-229.

Schemske, D.W., Mittelbach, G.G., Cornell, H.V., Sobel, J.M., Roy, K., 2009. Is there a latitudinal gradient in the importance of biotic interactions? Annu. Rev. Ecol. Evol. Syst. 40, 245-269.

Siqueira, A.C., Oliveira-Santos, L.G.R., Cowman, P.F., Floeter, S.R., 2016. Evolutionary processes underlying latitudinal differences in reef fish biodiversity. Global Ecol. Biogeogr. 25, 1466-1476.

Stegen, J.C., Lin, X., Konopka, A.E., Fredrickson, J.K., 2012. Stochastic and deterministic assembly processes in subsurface microbial communities. ISME J. 9, 1653-1664.

Vamosi, S.M., Heard, S.B., Vamosi, J.C., Webb, C.O., 2009. Emerging patterns in the comparative analysis of phylogenetic community structure. Mol. Ecol. 18, 572-592.

Webb, C.O., 2000. Exploring the phylogenetic structure of ecological communities: an example for rain forest trees. Am. Nat. 156, 145-155.

Webb, C.O., Ackerly, D.D., McPeek, M., Donoghue, M.J., 2002. Phylogenies and community ecology. Annu. Rev. Ecol. Evol. Syst. 33, 475-505.

Wiens, J.J., Donoghue, M.J., 2004. Historical biogeography, ecology and species richness. Trends Ecol. Evol. 19, 639-644.

Willig, M.R., Kaufman, D.M., Stevens, R.D., 2003. Latitudinal gradients of biodiversity: pattern, process, scale, and synthesis. Annu. Rev. Ecol. Evol. Syst. 34, 273-309. 